\title{
Characteristics of Thiol-Functionalized Mesoporous Silica and Its Application to Silver and Cadmium Ion Removal
}

\author{
Jayhyun Park, Hyunjung Kim, and Jaikoo Park
}

\begin{abstract}
An uptake of silver and cadmium from aqueous solutions by ion exchange on functionalized large pore mesoporous silica has been studied. Mesoporous silica with large pore (about $6 \mathrm{~nm}$ ) was synthesized by condensation of siliceous solution using nonionic oligomeric polyethylene glycol block copolymer (P123) as surfactant in acidic medium and was functionalized by 3-mercaptopropyltrimetoxysilane (MPTMS) on surface of silica for good selectivity and high adsorption capacity. The result of nitrogen gas adsorption (BET) and transition electron microscopy (TEM) show that silica adsorbate have ordered mesoporous structure with uniform pore size distribution. ${ }^{29}$ Si MAS NMR, TG and FT-IR confirm the functionalization of MPTMS on the surface of mesoporous silica. The removal efficiency of metal in various concentration of metal cations in aqueous solution was investigated and it is determined that in various concentration range, adsorption amount of metal cations on mesoporous silica match to Freundlich and Henry adsorption isotherm data which are used for calculation of ion exchange parameter.
\end{abstract}

Index Terms-Silver, adsorption, mesoporous, thiol.

\section{INTRODUCTION}

The optimization of wastewater treatment process requires a development of new operations based on low cost materials with high pollutant-removal efficiency [1]. The removal of toxic heavy metals for purification of water and wastewater, and the recovery of heavy valuable metals in the wastewater process can often result in cost saving [2]. Numerous processes such as ion exchange, precipitation, adsorption, ultrafiltration or reverse osmosis have been used for removing heavy metal ions [3-6]. These techniques have been successful, but they offer the disadvantages related to removal efficiency and in the majority of the cases, the process is not a recovery but really an elimination of metal. A lot of adsorbents including activated carbon, clays or zeolites are used for capture of metal ions, even though they have

Manuscript received January 13, 2012; revised February 20, 2012. This work was supported by the Mine Reclamation Corporation Research Fund (Project title: Development of an Improved Gravity Concentration Process for Fine Tailings) and by grant No. RTI104-01-04 from the Regional Technology Innovation Program of the Ministry of Knowledge Economy (MKE).

Jayhyun Park is with the R\&D Team, Institute of Mine Reclamation Corporation, Coal Center, 30 Chungjin-dong, Jongno-gu, Seoul 110-727, Republic of Korea (e-mail: jayhp@mireco.or.kr).

Hyunjung Kim is with Department of Mineral Resources and Energy Engineering, Chonbuk National University, 664-14 Duckjin-Dong 1Ga, Duckjin-Gu, Jeonju, Jeonbuk 561-756, Republic of Korea (e-mail: kshjkim@jbnu.ac.kr, corresponding author).

Jaikoo Park is with the Department of Natural Resources and Environmental Engineering, Hanyang University, \#17 Heangdang-dong, Seongdong-gu, Seoul 133-791, Republic of Korea (e-mail: jkpark@hanyang.ac.kr, corresponding author). their inherent disadvantages which are wide distribution of pore size, heterogeneous pore structure, low selectivity, heterogeneous reactions and relatively low metal loading capacities. These limitations ruled out the possibility of heavy metal recovery or recycle in wastewater solution because of the economical efficiency.

The use of functionalized mesoporous silica (FMS) materials as potential sorbents for the removal of heavy metal has been investigated recently [6-10]. Since the first report of the mesoporous materials surface modified with functional group [11], their synthesis and applications have attracted great interest because of the combined advantages of inorganic-organic composites and the mesoporous structure [12]. The uniformly distributed functional group in the mesoporous framework will impart the mesoporous materials with unique properties. Their large surface area, uniform pore size distributions and open-framework pore structure make them potential environmental material candidates in the field of advanced catalysis and adsorption. The functionalization of mesoporous silicas has been mostly studied with a mercaptopropyl group [13-16]. Wang and Stein reported that mesoporous silica (MCM-41) was functionalized with mercaptopropyl groups and its mercury loading was of $2.5 \mathrm{mmol} \mathrm{g}^{-1}[16,17]$. After that, a number of FMS for heavy metal loading were synthesized with pore sizes less than $3 \mathrm{~nm}$ though Yang reported that FMS with pore size larger than $3 \mathrm{~nm}$ also has good selectivity of $\mathrm{Hg}$ and $\mathrm{Cd}$ [10]. Furthermore, main targeted metal ions onto FMS were mercury, cadmium, lead and zinc [18-20] and most of these investigations focus on the metal loading amount, selectivity and the distribution coefficient of heavy metal $\left(\mathrm{K}_{\mathrm{d}}\right)$ but not adsorption isotherm.

In this work, silver and cadmium have been selected as target heavy metals. Silver is more valuable metal than general toxic heavy metal such as mercury, lead, zinc, cadmium and cromate. And silver is the highly potential adsorbate candidate for practical application of FMS in environmental field, because of its broad usage in the photographic and imaging industry, electronics, silverware and jewelry. Here we report the preparation of mesoporous silica with large pore size (about $6 \mathrm{~nm}$ ) by condensation of siliceous solution in acidic medium using nonionic oligomeric polyethylene glycol block copolymer (P123) as surfactant and the functionalization of 3-mercapto propyl trimetoxy silane (MPTMS) on the surface of mesoporous silica. The synthesized FMS materials were used as silver and cadmium ion adsorbents for application to aqueous solutions. Adsorption property of silver in FMS with large pore is also compared with that of cadmium which is known as one of high favorable metal cations on FMS. 


\section{MATERIALS AND MethodS}

\section{A. Absorbent Synthesis Procedure}

Zhao et al. [21] showed that non-ionic surfactants are good structure-directing agents of mesoporous silicate. In a typical preparation, $4 \mathrm{~g}$ of Pluronic P123 (Aldrich Co.) was dissolved in $120 \mathrm{~g}$ of $2 \mathrm{M} \mathrm{HCl}$ solution with stirring at room temperature. Then, $46 \mathrm{~g}$ of silicate solution made by dissolving $1 \mathrm{M}$ of solid state amorphous silica (Dongyang Chem. Co.) in $1 \mathrm{M} \mathrm{NaOH}$ solution was added into the solution with stirring at $35 \mathrm{oC}$ for $20 \mathrm{~h}$. The mixture was aged at $90 \mathrm{oC}$ for $20 \mathrm{~h}$ without stirring. The precipitated solid product was recovered, washed, and dried at 60 oC. Dried samples were calcined at $550 \mathrm{oC}$ for $2 \mathrm{~h}$. The functionalization of thiol groups was followed by stirring the mesoporous silica in toluene. An $8 \mathrm{~g}$ of sample of the surfactant extracted mesoporous silica was then stirred for 24 $\mathrm{h}$ in $200 \mathrm{~mL}$ of toluene containing $8 \mathrm{~g}$ of MPTMS at $30 \mathrm{oC}$. The products were filtered, and washed with copious amount of ethanol to remove ungrafted MPTMS.

\section{B. Adsorption Test}

The aqueous solutions of silver $(\mathrm{AgNO} 3)$ and cadmium (CdNO3) used in all experiments were prepared with deionised water. A $0.1 \mathrm{~g}$ of mesoporous sample was poured in $50 \mathrm{~mL}$ of metallic solution in a glass bottle. The mixture solutions were shaken for $6 \mathrm{~h}$ allowing the adsorption to reach equilibrium at $25 \mathrm{oC}$. The $\mathrm{pH}$ value in all experiments was fixed at 5.5 using buffer solutions. The mixture was filtered afterwards. The initial and final metal concentrations of the solutions were measured with an ICP-AES (ICPS-1000IV, Shimadzu). Several metal cation solutions with different initial concentration were prepared.

\section{Characterization}

The images of the IR transmission spectra were determined in transmission mode using potassium bromide based disk pellets prepared by mixing $\mathrm{KBr}$ powder with sample powder. The spectra were measured in the range of $4000 \mathrm{~cm}^{-1}-400 \mathrm{~cm}^{-1}$, with a resolution of $2 \mathrm{~cm}^{-1}$, using a Fourier transform infrared spectrometer (Nicolet, Omnic 405 Model). Thermogravimetric analyses of the samples were performed with a TA Instruments SDT2960. The sample for TG was not calcined to avoid the other thermal effect. The extraction with ethanol took the place of the calcination for removal of surfactant. In order to remove the surfactant, $3 \mathrm{~g}$ of solid was treated with $500 \mathrm{~mL}$ of ethanol at room temperature for $16 \mathrm{~h}$, then filtered, washed and dried. The sample powders were heated in flowing air from ambient temperature to $400{ }^{\circ} \mathrm{C}$ at a rate of $5{ }^{\circ} \mathrm{C} \mathrm{min}{ }^{-1}$. The surface and shape of the mesoporous samples were observed with a field-emission scanning electron microscope (JSM-6330F, JEOL). The specific surface area was measured with the $\mathrm{N}_{2}$-gas adsorption method applying the BET apparatus (Nova1000, Quantachrome). The pore size distribution was calculated by the BJH method.

\section{RESULTS AND DISCUSSION}

\section{A. Adsorbent Structural Characterization}

All materials were prepared at a very low $\mathrm{pH}(<1)$. Fig. 1a shows the morphology of mesoporous material. The aggregates of synthesized mesoporous materials had long fabric like shape. TEM image of synthesized material confirm the existence of the ordered pore structures in the material (Fig. 1b).

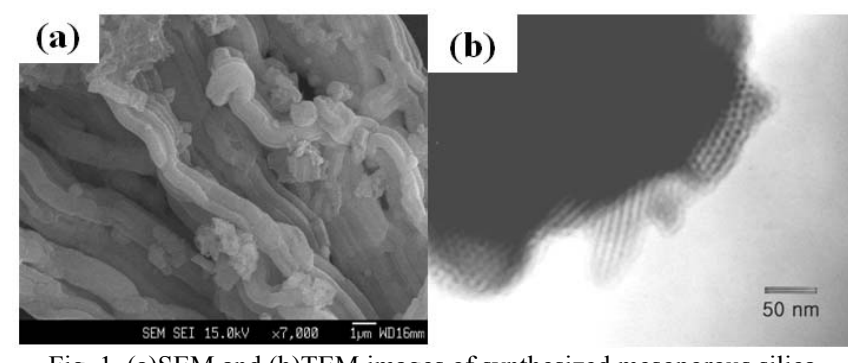

Fig. 1. (a)SEM and (b)TEM images of synthesized mesoporous silica material

The nitrogen adsorption-desorption isotherms and the pore size distribution of the synthesized material and functionalized materials are shown in Fig. 2.

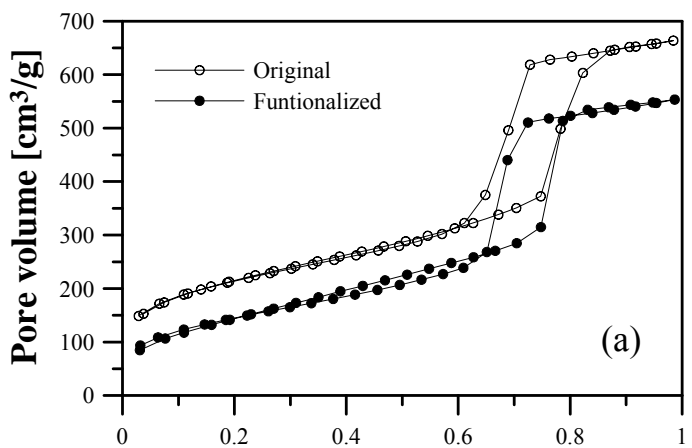

Relative pressure $\left[\mathbf{P} / \mathbf{P}_{0}\right]$

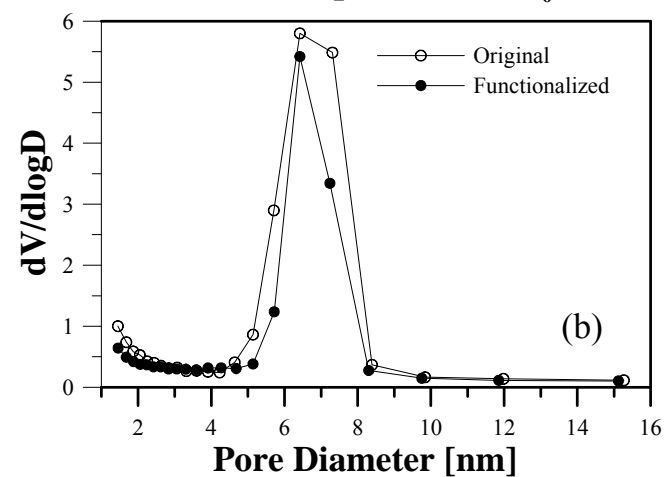

Fig. 2. (a) Nitrogen isotherms of samples and their (b) pore size distributions by BJH method

TABLE I: TEXTURAL PROPERTIES OF THE MESOPOROUS SILICA MATERIALS

\begin{tabular}{cccc}
\hline \hline Sample & $\begin{array}{c}\text { BET surface } \\
\text { area }\left(\mathrm{m}^{2} / \mathrm{g}\right)\end{array}$ & $\begin{array}{c}\text { Pore volume } \\
\left(\mathrm{cm}^{3} / \mathrm{g}\right)\end{array}$ & $\begin{array}{c}\text { Mesopore } \\
\text { diameter }(\mathrm{nm})\end{array}$ \\
\hline Original & 768 & 1.03 & 6.42 \\
Functionalized & 538 & 0.85 & 6.42 \\
\hline \hline
\end{tabular}

The adsorption-desorption isotherms exhibit typical Type IV isotherm patterns which is typical characteristic of a mesoporous material. The one steep slope at $0.7-0.8$ of $\mathrm{P} / \mathrm{P}_{0}$ is characteristic of the porous adsorbents possessing narrow 
size distribution of pores, approximately $6.4 \mathrm{~nm}$. They also showed a type A hysteresis loop of de Boer located at higher relatively pressure than that of the MCM-41 material. It is known that this kind of hysteresis loop is due to cylindrical pores open at both ends [22]. This hysteresis is caused by condensation and evaporation of a hemispherical meniscus produced in cylindrical pores. Fig. 2 and Table 1 show that the surface modification process by MPTMS brought about a decrease in the nitrogen adsorption capacity, reflected in a decrease in the specific surface area and pore volume of the sample. However, the mesopore diameter and the height of hysteresis which is in proportion to the mesopore volume don't reduce at all after functionalization. The specific surface area and pore volume of the original mesoporous sample were about $768 \mathrm{~m}^{2} / \mathrm{g}$ and $1.03 \mathrm{~cm}^{3} / \mathrm{g}$ respectively. These results indicate that MPTMS functionalization have an effect on the reduction of micro-pore volume without any remarkable change on the structural ordering of mesopore and narrow meso-pore size distributions of silica mesoporous materials.

\section{B. Adsorbent Compositional Characterization}

The surfaces of the mesoporous silica before and after the functionalization were characterized by FT-IR (Fig. 3).

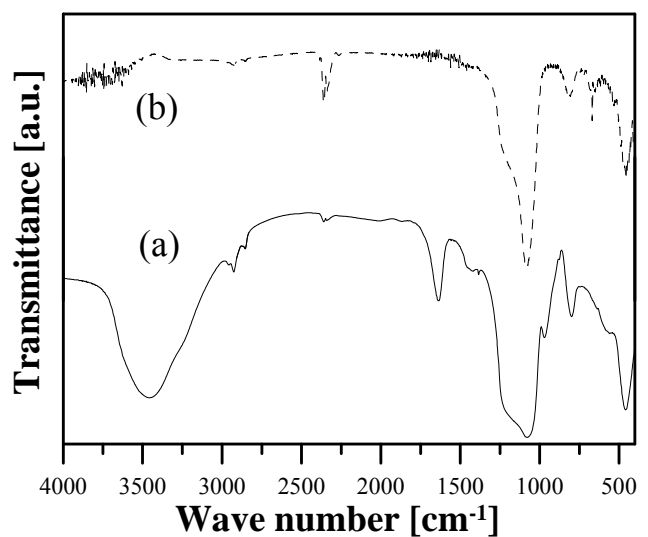

Fig. 3. FT-IR results of surfactant free mesoporous materials: (a) original and (b) functionalized

The spectrum of the original mesoporous material was similar to that of amorphous silica. The bands at $798 \mathrm{~cm}^{-1}$ and $450 \mathrm{~cm}^{-1}$ were due to Si-O-Si symmetric stretching and bending vibrations, respectively. The band at $950 \mathrm{~cm}^{-1}$ and $570 \mathrm{~cm}^{-1}$ was due to $\mathrm{Si}-\mathrm{OH}$ stretching and $\mathrm{Si}-\mathrm{OH}$ vibration [23]. The sharp band at $1635 \mathrm{~cm}^{-1}$ attributed to deformated water that interacted through hydrogen bonds with silanol groups was disappeared for the MPTMS functioalized samples. After functionalization, the $\mathrm{Si}-\mathrm{OH}$ related peaks which were at $570 \mathrm{~cm}^{-1}$ and $950 \mathrm{~cm}^{-1}$ disappeared. But the siloxane (Si-O-Si) peaks which appeared at $450 \mathrm{~cm}^{-1}, 798$ $\mathrm{cm}^{-1}$ and $1070 \mathrm{~cm}^{-1}$ had been kept after functionalaization. The broad band in range of $3000-3750 \mathrm{~cm}^{-1}$ was associated with the silanol stretching of surface and vibrational structure of siloxane by water molecule adsorption on silica surface. This broad band for MPTMS modified samples almost disappeared comparing to that of the original sample. It indicates that the surface of thiol modified samples, comparing to the original sample, is so hydrophobic that it significantly inhibit water molecule adsorption. After surfactant removal process by washing with ethanol, the surfactant in unfunctionalized sample was remained as evidenced by appearing the $\mathrm{C}-\mathrm{H}$ vibrations in the range of $2920-2875 \mathrm{~cm}^{-1}$ and at $1375 \mathrm{~cm}^{-1}$. It is hard to comment that the small peaks in the range of $2920-2875 \mathrm{~cm}^{-1}$ in the functionalized silica may be due to the functionalization of mercaptopropyl group. Because the $\mathrm{C}-\mathrm{H}$ vibrations of the mercaptopropyl group of functionalized sample in the range of $2926-2880 \mathrm{~cm}^{-1}$ are overlapped with the $\mathrm{C}-\mathrm{H}$ vibrations due to the remained surfactant. But, the $\mathrm{CH}_{2}$ rocking vibration of $\mathrm{Si}-\mathrm{CH}_{2} \mathrm{R}$ appeared at $690 \mathrm{~cm}^{-1}$ in the funtionalized silica. Therefore, these $\mathrm{C}-\mathrm{H}$ vibrations of the mercaptopropyl groups and the disappearance of silanol groups for material modified with MPTMS suggest that MPTMS is anchored well on the surface of silica.

${ }^{29} \mathrm{Si}-\mathrm{MAS}-\mathrm{NMR}$ technique was also used employed to investigate the surface information on functionalized silica (Fig. 4). The ${ }^{29} \mathrm{Si}$ NMR spectra for original sample shows that the $\mathrm{Q}_{2}$ signal derived from silandiol $\left(\mathrm{Si}(\mathrm{OH})_{2}\right)$ group exists a little and that the silanol group $\left(\mathrm{Si}-\mathrm{OH}, \mathrm{Q}_{3}\right)$ is more than the siloxane ( $\left.\mathrm{Si}-\mathrm{O}-\mathrm{Si}, \mathrm{Q}_{4}\right)$ group on silica surface. The Si-NMR signals of functionalized sample display higher $\mathrm{Q}_{4}$ signal than $\mathrm{Q}_{3}$ signal and disappearance of $\mathrm{Q}_{2}$ signal. These results mean that MPTMS react with the active silanol and the silandiol groups.

\section{$\mathbf{Q}_{4}$

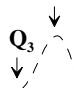

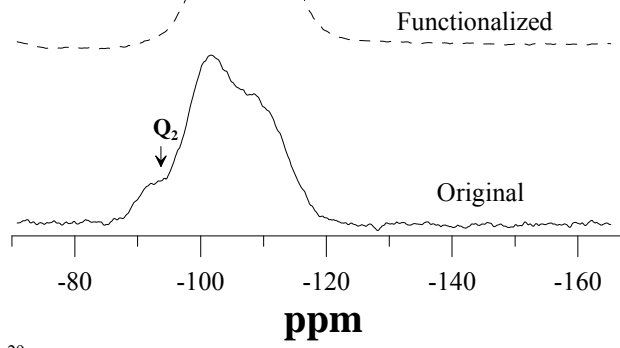

Fig. $4 .{ }^{29}$ Si-MAS-NMR of surfactant free mesoporous silica absorbents

\section{Thermogravimetric Analysis}

Thermogravimetric analysis of the samples before and after functionalization was conducted. The weight loss below $70{ }^{\circ} \mathrm{C}$ in Fig. 5a is due to the removal of physisorbed water. There are rarely weight loss of this temperature part for the functionalized sample, indicating that the surface of silica come to be hydrophobic by functionalization. The original mesoporous material rapidly lost weight at between $230{ }^{\circ} \mathrm{C}$ and $280{ }^{\circ} \mathrm{C}$ (Fig. 5a). Weight loss in this range may be due to the removal of surfactant. It was considered that surfactant was still remained in the pore structure of mesoporous silica, though surfactant had been washed out with ethanol several times. Fig. 5 show that the weight loss of the MPTMS modified sample is different from that of the original material. The functionalized sample showed broader weight losses than that of the original mesoporous silica through the temperature range from 230 to $350{ }^{\circ} \mathrm{C}$ (Fig. 5b). Its weight loss could be assigned to the decomposition of unwashed surfactant and attached propylthiol group on silica surface. 

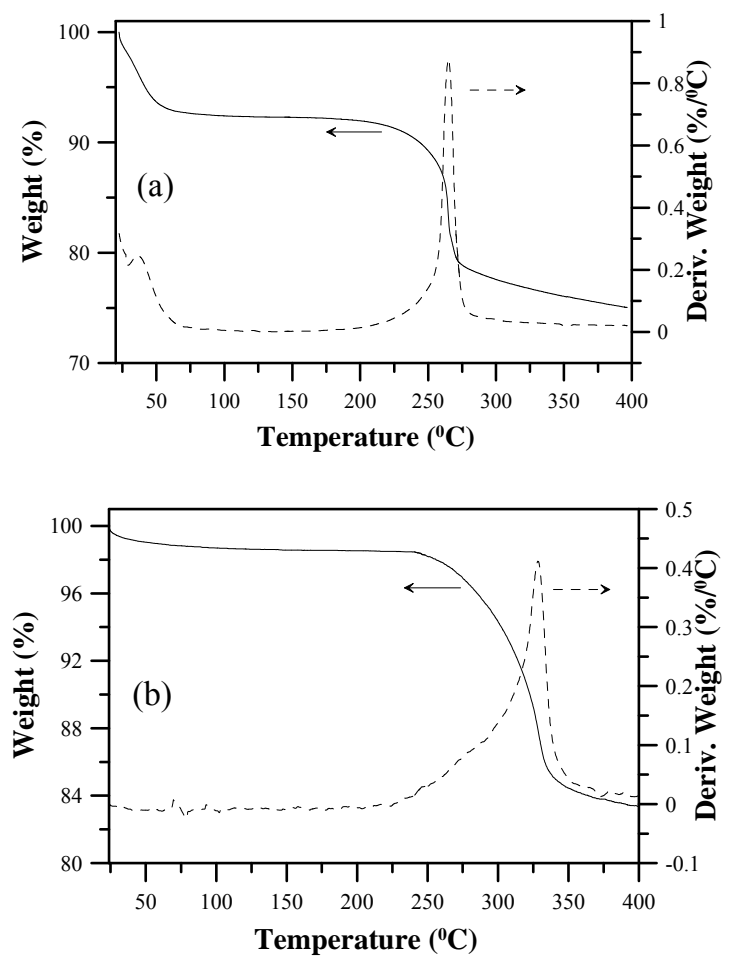

Fig. 5. Thermogravimetric analysis of (a) original and (b) thiol functionalized mesoporous silica.

\section{Adsorption of Cations on Mesoporous Silica}

Silver and cadmium ions adsorption capacities of functional mesoporous silica were investigated. The ion removal efficiency in solution at $30{ }^{\circ} \mathrm{C}$ by varying the ion concentration from 10 to $500 \mathrm{mg} / \mathrm{L}$ is shown in Fig. 6. The removal efficiencies in Fig. 6 were calculated using the following equations (1).

$$
\text { Removal efficiency } \left.(\%)=\left(\mathrm{C}_{\mathrm{i}}-\mathrm{C}_{\mathrm{f}}\right) / \mathrm{C}_{\mathrm{f}}\right) \times 100
$$

where, $\mathrm{C}_{\mathrm{i}}$ and $\mathrm{C}_{\mathrm{f}}$ represent the concentrations $(\mathrm{mg} / \mathrm{L})$ of the metal ion in initial and final solutions, respectively.

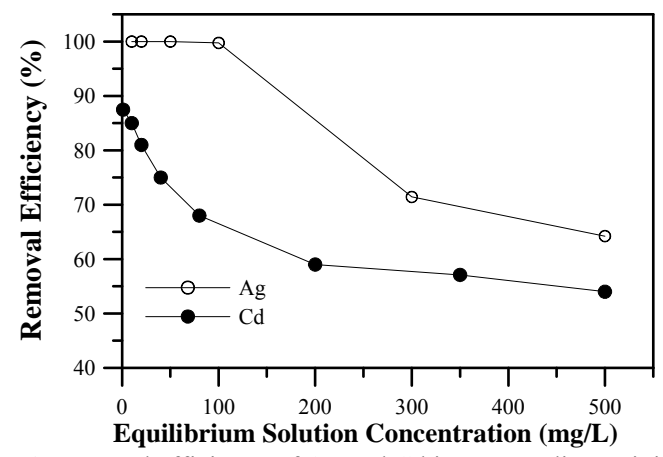

Fig. 6. Removal efficiency of $\mathrm{Ag}$ and $\mathrm{Cd}$ ions according to initial concentration.

The removal efficiencies for silver and cadmium ion decrease with increasing metal ion concentration in aqueous solutions. The removal efficiency of silver was higher than that of cadmium. When the Ag concentrations of the influent water were under $100 \mathrm{mg} / \mathrm{L}$, the $\mathrm{Ag}$ concentrations of effluent water were under $0.1 \mathrm{mg} / \mathrm{L}$ after ion exchange processes of adsorbent sample. This result indicate that thiol functionalized mesoporous silica is the efficient adsorbent of $\mathrm{Ag}$ ions more than $\mathrm{Cd}$ ion from water containing lower metal concentrations.
The isotherms of adsorption of metal ions on the thiol modified mesoporous silica are shown in Fig. 7. Silver and cadmium adsorption capacity continued to increase with the rise in the influent concentration, indicating that strong interaction took place between the ion exchangeable thiol surface and the added metal cations. The relationships between the metal concentrations in water and the adsorbed amounts of metal can be approximated to the straight lines. Therefore, these adsorption isotherms can be expressed by Henry equation or Freundlich equation. The adsorption data for silver cations over the concentration range from 10 to 500 $\mathrm{mg} / \mathrm{L}$ at $30{ }^{\circ} \mathrm{C}$ have been correlated with Henry equation (2) [24].

$$
\mathrm{C}_{\mathrm{ads}}=\mathrm{K}_{\mathrm{h}} \mathrm{C}_{\mathrm{e}}
$$

where $\mathrm{K}_{\mathrm{h}}$ is an adsorption constant, $\mathrm{C}_{\mathrm{ads}}$ is an adsorbed amount of metal on the adsorbent $(\mathrm{mg} / \mathrm{g})$ and $\mathrm{C}_{\mathrm{e}}$ is the equilibrium concentration of metal in solution $(\mathrm{mg} / \mathrm{L})$. The adsorption constants and statistical fits of the sorption data to the Henry equation are given in Table 2 . The Henry equation effectively described the adsorption data with all $\mathrm{R}^{2}$ values $>0.98$.

The Freundlich adsorption isotherm, one of the most widely used isotherms, has been used for fitting the adsorption data over a wide range of concentrations. This isotherm gives an expression encompassing the adsorption on the non-uniform surface of adsorbent. The Freundlich adsorption model was also applied to the removal on the silver and cadmium cations (Fig. 7). The constant of Freundlich can be evaluated by linearization of $(3)[25,26]$.

$$
\ln \mathrm{C}_{\mathrm{ads}}=\ln \mathrm{K}_{\mathrm{f}}+1 / n \ln \mathrm{C}_{\mathrm{e}}
$$

The constants $\mathrm{K}_{\mathrm{f}}$ and $1 / \mathrm{n}$ were calculated and the obtained parameters are shown in Table 2. The coefficient $\mathrm{K}_{\mathrm{f}}$ is a parameter that reflects the amount of the active adsorption site. $1 / \mathrm{n}$ is a characteristic coefficient related to energy or intensity of adsorption [24,25].

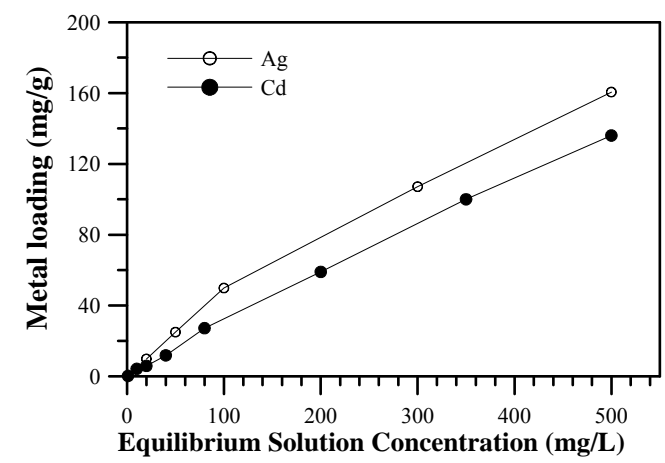

Fig. 7. Ag and $\mathrm{Cd}$ loading as a function of solution concentration

TABLE II: CONSTANTS OF ADSORPTION EQUATIONS FOR METAL CATIONS ON FUNCTIONALIZED MESOPOROUS SILICA

\begin{tabular}{cccccc}
\hline \hline \multirow{2}{*}{ Adsorbate } & \multicolumn{2}{c}{ Henry Eq. } & \multicolumn{3}{c}{ Freundlich Eq. } \\
\cline { 2 - 6 } & $\mathrm{K}_{\mathrm{h}}(\mathrm{L} / \mathrm{g})$ & $\mathrm{R}^{2}$ & $\begin{array}{c}\mathrm{K}_{\mathrm{f}} \\
(\mathrm{mg} / \mathrm{g})\end{array}$ & $1 / \mathrm{n}$ & $\mathrm{R}^{2}$ \\
\hline $\mathrm{Ag}$ & 0.337 & 0.989 & 0.846 & 0.831 & 0.996 \\
$\mathrm{Cd}$ & 0.279 & 0.998 & 0.071 & 0.990 & 0.994 \\
\hline \hline
\end{tabular}


The Freundlich model as well as the Henry model effectively described the adsorption data with almost value of $\mathrm{R}^{2}>0.99$. Moreover, the higher values of $\mathrm{K}_{\mathrm{f}}$ of adsorbed sample for $\mathrm{Ag}$ than that for $\mathrm{Cd}$ confirm the great affinity of the ions of silver towards the functionalized silica surface. This isotherm does not predict mathematically any saturation of the adsorbent surface; infinite surface coverage is plotted against $\ln \mathrm{C}_{\mathrm{e}}$, yielding a straight line indicating multilayer adsorption on the surface [27,28]. Thus the good agreement of isotherms with Freundlich and Henry model in quite high metal concentration range suggest that multilayer adsorption of metal ions takes place in uniform pore.

\section{CONCLUSIONS}

Thiol functional porous silica with pore size of $6 \mathrm{~nm}$ was synthesized for use as heavy metal cation adsorbent, and the silver and cadmium heavy metal loading capacities of this material were examined. After the functionalization of MPTMS, the specific surface area and pore volume of mesoporous silica decreased about $30 \%$ and $18 \%$ respectively. The FT-IR, Si MAS NMR and TG results showed that hydrophilic mesoporous silica surface $(\mathrm{Si}-\mathrm{OH})$ was replaced by hydrophobic MPTMS.

The removal efficiencies of $\mathrm{Ag}$ and $\mathrm{Cd}$ ions decrease with increasing metal ion concentration in aqueous solutions and it is concluded that FMS is efficient adsorbent of $\mathrm{Ag}$ than $\mathrm{Cd}$. The metal adsorption is also improved by increasing metal ion concentration in aqueous solutions. The Freundlich and Henry equations were used to describe the adsorption isotherms of single-solute system. The isotherms of adsorption obtained are in agreement with the models of Freundlich and Henry in the whole range of the concentrations studied. It is considered that multilayer adsorption of metal ions in uniform pore takes place as increasing of the metal concentration of solution, from this isotherm results.

\section{REFERENCES}

[1] J. Perić, M. Trgo, and N. Vulojević Medvidović, "Removal of zinc, copper and lead by natural zeolite-a comparison of adsorption isotherms," Water Research, vol. 38, pp. 1893-1899, Apr. 2004.

[2] B. W. Lee, Y. H. Kim, H. J. Lee, and J. H.Yi, "Synthesis of functionalized porous silicas via templating method as heavy metal ion adsorbents: the introduction of surface hydrophilicity onto the surface of adsorbents," Microporous and Mesoporous materials, vol. 50, pp. 77-90, Dec. 2001.

[3] B. Bournonville, A. Nzihou, P. Sharrock, and G. Depelsenaire, "Stabilisation of heavy metal containing dusts by reaction with phosphoric acid: study of the reactivity of fly ash," J. Hazardous Materials, vol. 116, pp. 65-74, Dec. 2004.

[4] H. A. Qdais and H. Moussa, "Removal of heavy metals from wastewater by membrane processes: a comparative study," Desalination, vol. 164, pp. 105-110, Apr. 2004.

[5] A. P. Kryvoruchko, I. D. Atamanenko, and L. Y. Yurlova, "Concentration purification of $\mathrm{Co}(\mathrm{II})$ ions by reverse osmosis and ultrafiltration combined with sorption on clay mineral montmorillonite and cation-exchange resin KU-2-8n," J. Membrane Sci., vol. 228, pp. 77-81, Jan. 2004.

[6] N. Chiron, R. Guilet, and E. Deydier, "Adsorption of $\mathrm{Cu}(\mathrm{II})$ and $\mathrm{Pb}(\mathrm{II})$ onto a grafted silica: isotherm and kinetic models," Water Research, vol. 37, pp. 3079-3086, Jul. 2003.
[7] L. Mercier and T. J. Pinnavaia, "A functionalized porous clay heterostructure for heavy metal ion $\left(\mathrm{Hg}^{2+}\right)$ trapping," Microporous \& Mesoporous Materials, vol. 20, pp. 101-106, Feb. 1998.

[8] J. Brown, R. Richer, and L. Mercier, "One-step synthesis of high capacity mesoporous $\mathrm{Hg}^{2+}$ adsorbents by non-ionic surfactant assembly," Microporous \& Mesoporous Materials, vol. 37, pp. 41-48, May 2000

[9] L. Bois, A. Bonhommé, A. Ribes, B. Pais, G. Raffin, and F. Tessier, "Functionalized silica for heavy metal ions adsorption," Colloids \& Surfaces A: Physicochemical \& Eng. Aspects, vol. 221, pp. 221-230, Jul. 2003.

[10] Q. Yang, J. Liu, J. Yang, L. Zhang, Z. Feng, J. Zhang, and C. Li, “Acid catalyzed synthesis of ordered bifunctionalized mesoporous organosilicas with large pore," Microporous \& Mesoporous Mater., vol. 77, pp. 257-264, Jan. 2005.

[11] X. Feng, G. E. Fryxell, L.-Q. Wang, A. Y. Kim, J. Liu, and K. M. Kemmer, "Functionalized monolayers on ordered mesoporous supports," Science, vol. 276, pp. 923-925, May 1997.

[12] A. Sayari, S. Hamoudi, Y. Yang, I. L. Moudrakovski, and J. R. Ripmeester, "New insights into the synthesis, morphology, and growth of periodic mesoporous organosilicas," Chem. Mater., vol. 12, pp. 3857-3863, Dec. 2000.

[13] L. Mercier and T. J. Pinnavaia, "Access in mesoporous materials: advantages of a uniform pore structure in the design of a heavy metal ion adsorbent for environmental remediation," Adv. Mater., vol. 9, pp. 500-503, May 1997.

[14] A. Bibby and L. Mercier, "Mercury(II) ion adsorption behavior in thiol-functionalized mesoporous silica microspheres," Chem. Mater., vol. 14, pp. 1591-1597, Apr. 2002.

[15] G. E. Fryxell, J. Liu, T. A. Hauser, Z. Nie, and K. F. Ferris, "Design and synthesis of selective mesoporous anion traps," Chem. Mater., vol. 11, pp. 2148-2154, Aug. 1999.

[16] J. Liu, X. D. Feng, G. E. Fryxell, and L. Q. Wang, "Hybrid mesoporous materials with functionalized monolayers," Chem. Eng. Technol., vol. 21, pp. 97-100, Jan. 1998.

[17] M. H. Lim, C. F. Blanford, and A. Stein, "Synthesis and characterization of a reactive vinyl-functionalized MCM-41: probing the internal pore structure by a bromination reaction," J. Am. Chem. Soc., vol. 119, pp. 4090-4091, Apr. 1997.

[18] J. Brown, L. Mercier, and T. J. Pinnavaia, "Selective adsorption of $\mathrm{Hg}^{2+}$ by thiol-functionalized nanoporous silica," Chem. Commun., no. 1, pp. 69-70, Jan. 1999.

[19] L. Mercier, and T. J. Pinnavaia, "Heavy metal ion adsorbents formed by the grafting of a thiol functionality to mesoporous silica molecular sieves: factors affecting $\mathrm{Hg}(\mathrm{II})$ uptake," Environ. Sci. Technol., vol. 32, pp. 2749-2754, Sep. 1998.

[20] V. Antochshuk and M. Jaroniec, "1-Allyl-3-propylthiourea modified mesoporous silica for mercury removal," Chem. Commun., no. 3, pp. 258-259, Jan. 2002.

[21] D. Zhao, Q. Huo, J. Feng, B. F. Chmelka, and G. D. Stucky, "Nonionic triblock and star diblock copolymer and oligomeric surfactant syntheses of highly ordered, hydrothermally stable, mesoporous silica structures," J. Am. Chem. Soc., vol. 120, pp. 6024-6036, Jun. 1998.

[22] S. Lowell and J. E. Shields, Powder Surface Area and Porosity, 3rd ed. London: Chapman \& Hall, 1991, pp. 56.

[23] J. Jeon, S. C. Yi, and S. G. Oh, "Preparation and antibacterial effects of $\mathrm{Ag}-\mathrm{SiO}_{2}$ thin films by sol - gel method," Biomaterials, vol. 24, pp. 4921-4928, Dec. 2003.

[24] K. Kibe, M. Takahashi, T. Kameya, and K. Urano, "Adsorption equilibriums of principal herbicides on paddy soils in Japan," The Sci. of Total Environment, vol. 263, pp. 115-125, Dec. 2000.

[25] E. Erdem, N. Karapinar, and R. Donat, "The removal of heavy metal cations by natural zeolites," J. Colloid \& Interface Sci., vol. 280, pp. 309-314, Dec. 2004.

[26] H. Hadjar, B. Hamdi, and Z. Kessaissia, "Adsorption of heavy metal ions on composite materials prepared by modification of natural silica," Desalination, vol. 167, pp. 165-174, Aug. 2004.

[27] S. M. Hasany, M. M. Saeed, and M. Ahmed, "Sorption of traces of silver ions onto polyurethane foam from acidic solution," Tantala, vol. 54, pp. 89-98, Mar. 2001.

[28] S. M. Hasany, M. M. Saeed, and M. Ahmed, "Sorption and thermodynamic behavior of zinc(II)-thiocyanate complexes onto polyurethane foam from acidic solutions," J. Radioanal. Nucl. Chem., vol. 252 , pp. $477-484$, Jun. 2002. 